\title{
USO DE FERRAMENTAS DIGITAIS DE CRIAÇÃO DE NARRATIVAS NA FORMAÇÃO DOCENTE
}

\author{
Evani Andreatta Amaral Camargo ${ }^{1}$ \\ Maíra Valencise Gregolin²
}

\section{RESUMO}

O presente artigo tem como finalidade apresentar reflexões quanto ao uso de tecnologias digitais em ambientes educacionais, em que há alunos em processo de inclusão, com o olhar direcionado à formação docente. Nessa investigação, procuramos compreender como os docentes se apropriam das tecnologias em seus contextos de aula, em suas práticas pedagógicas no cotidiano, de maneira que nos forneça bases norteadoras para a formação docente quanto ao uso de ferramentas de criação de narrativas digitais. Levantamos questões que orientaram nossa reflexão, procurando entender de que maneira o uso dessas ferramentas possibilitaria ao professor elaborar estratégias que favoreçam a inclusão. Ao conduzir as práticas pedagógicas, procuramos compreender como essas ferramentas poderiam servir de suporte ao professor. A fundamentação teórica resgata importantes autores dos temas que permeiam a pesquisa. A ecologia das mídias, escola do pensamento científico que permitem essa reflexão, tem se destacado pela ênfase no estudo do impacto cultural das tecnologias e dos meios de comunicação nas sociedades, por uma perspectiva histórica dos meios. Olhamos os dados sob a perspectiva histórico-cultural, em que a análise é interpretativa, instaurada em um contexto sócio-histórico. Utilizamos a metodologia qualitativa de pesquisa tendo como instrumentos de coleta as notas de campo, o grupo focal e entrevistas. Conduzimos intervenções com uso dos aplicativos Toontastic e Educreations. Procuramos identificar as principais dificuldades observadas pelos professores, suas reflexões quanto às suas práticas e possibilidades de transformação. Os resultados obtidos até o momento são encorajadores, indicando que as ferramentas digitais, como Educreations e Toontastic enquanto instrumento de acessibilidade e inclusão, podem auxiliar o professor favorecendo a comunicação e socialização entre os aprendizes. Como impacto direto da experiências conduzidas, identificamos que as professoras sentiram-se seguras e motivadas em modificar suas práticas e experimentar novas formas de ensinar.

1 Centro Universitário Moura Lacerda. valencise@gmail.com

2 Centro Universitário Moura Lacerda. valencise@gmail.com

Criar Educação, Criciúma, v. 8, nº1, jan/jul 2019.- PPGE - UNESC 


\section{CRIAR EDUCAÇÃOO \\ Revista do Programa de Pós-Graduação em Educação - UNESC}

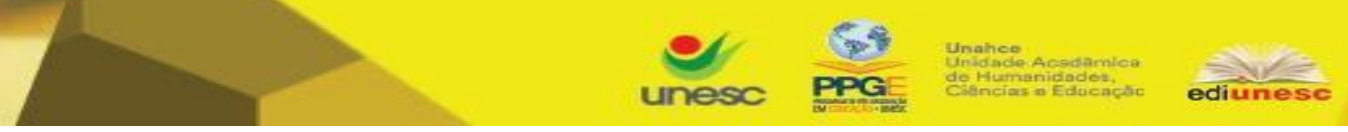

Palavras-chave: Ferramentas digitais. Narrativas digitais. Formação docente. Perspectiva histórico-cultural

\section{THE USE OF TOOLS TO CREATE DIGITAL STORYTELLING IN TEACHER EDUCATION}

The purpose of this article is to present reflections on the use of digital technologies in educational environments, where there are students in the process of inclusion, with a focus on teacher education. In this research, we seek to understand how teachers appropriate technologies in their classroom contexts, in their daily pedagogical practices, in a way that provides us with guiding bases for teacher training in the use of digital storytelling creation tools. We raised questions that guided our reflection, trying to understand how the use of these tools would enable the teacher to develop strategies that favor inclusion. In conducting pedagogical practices, we try to understand how these tools could be used to support the teacher. The theoretical foundation rescues important authors of the themes that permeate the research. The ecology of the media, a school of scientific thought that allows this reflection, has been highlighted by the emphasis on the study of the cultural impact of technologies and media in societies, through a historical perspective of the media. We look at the data from the historical-cultural perspective, in which the analysis is interpretive, established in a socio-historical context. We used the qualitative methodology of research, having as instruments of collection the field notes, the focus group and interviews. We conduct interventions using the Toontastic and Educreations applications. We sought to identify the main difficulties observed by teachers, their reflections on their practices and possibilities for transformation. The results obtained so far are encouraging, indicating that digital tools, such as Educreations and Toontastic as an instrument of accessibility and inclusion, can help the teacher by promoting communication and socialization among learners. As a direct impact of the experiences we have conducted, we have identified that teachers have felt secure and motivated in modifying their practices and experiencing new ways of teaching.

Keywords: Digital tools. Storytelling. Teacher practices. Historic-cultural perspective

\section{INTRODUÇÃO E PRESSUPOSTOS TEÓRICOS}

Nossa investigação integra pesquisa de pós-doutorado financiada pela CAPES/PNPD e parte do pressuposto de que a vida cotidiana hiperconectada se 


\section{CRIAR EDUCAÇÃOO Revista do Programa de Pós-Graduação em Educação - UNESC}

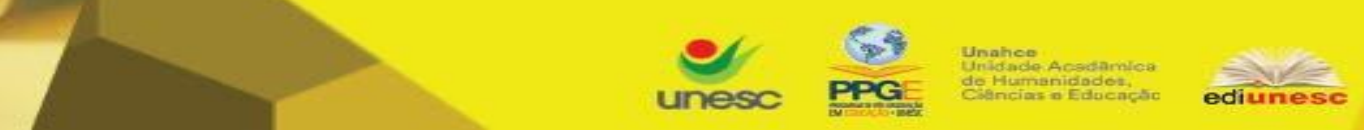

estabelece em espaços midiáticos não lineares com infinitas possibilidades de conexões, condicionando o sujeito a um novo conjunto articulado de competências e habilidades para lidar com a realidade. (FLORIDI, 2015)

As transformações provocadas pelo desenvolvimento das tecnologias digitais nos meios de comunicação, na criação artística e no mercado educacional são uma realidade que tem chamado a atenção de vários estudiosos.

Assim, este artigo tem o objetivo de propor e aprofundar algumas discussões quanto ao uso de tecnologias digitais em ambientes educacionais, em que há alunos em processo de inclusão, com o olhar direcionado à formação docente.

Atualmente, empreender uma investigação sobre o uso das mídias digitais no contexto da educação é essencial, pois tornou-se impossível imaginar a sociedade contemporânea sem a presença maciça de informações ou a intervenção constante das mídias na vida pessoal e social.

No entanto, não devemos cair no equívoco de acreditar que as transformações culturais são devidas apenas ao advento das tecnologias e meios de comunicação e cultura. Cada tecnologia de linguagem deu origem a processos semióticos específicos, por isso, são os tipos de signos que circulam nesses meios, os tipos de mensagens e processos de comunicação que neles se engendram os verdadeiros responsáveis não só por moldar o pensamento e a sensibilidade dos seres humanos, mas também por propiciar o surgimento de novos ambientes sócio-culturais.

Pela perspectiva histórico-cultural, o homem não é reflexo apenas de seu aparato biológico, mas já nasce no mundo cultural, constituindo-se na relação entre essas duas esferas, no uso das ferramentas, que também compõe a característica específica humana, que dá origem à linguagem (PINO, 2000). Como apontado por Vigotski (2001, 2007), a estrutura e a formação da atividade psíquica realizam-se no processo do desenvolvimento social da criança, em colaboração com o meio social com o qual ela se relaciona, o que resulta na organização das funções mentais superiores (linguagem, cognição e memória volitiva, por exemplo). Faz-se necessário tal contato; e o desenvolvimento, para este autor, decorre do aprendizado, que, por sua vez, em uma 


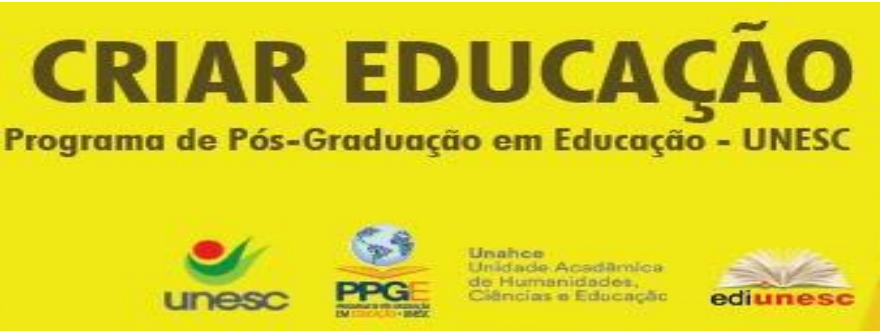

inter-relação dinâmica, é impulsionado pelo desenvolvimento anterior. Desta forma, aprendizado e desenvolvimento ocorrem no processo de mediação, em colaboração com o outro, ou no contato com os objetos e signos culturais. Para o autor (VIGOTSKI, 1997), um sujeito com limitações e com um potencial biológico diferente dos demais pode ter os rumos de seu desenvolvimento modificados e com melhor expectativa em função do entorno sócio-histórico, do modo como as pessoas o encaram e em função do que se espera dele.

Se voltarmos à origem das mídias, na melhor das hipóteses, começa com uma boa história em torno de uma fogueira. A narrativa começa com o início da humanidade, no momento em que os homens passam a se comunicar e contar histórias. Não existem relatos de uma civilização, classe ou grupo social sequer, em qualquer lugar do planeta, que não tenha pautado seu desenvolvimento nas narrativas. Kittler (2005) nos mostra como as transformações técnicas definiram, desde a Antiguidade, mudanças sociais, delineando um percurso do manuscrito (com seus diferentes suportes, como a argila, a pedra e, mais tarde, o papel) ao impresso, em que se processou uma intensa modificação nas formas de viver e sentir o mundo, já que uma civilização centrada na oralidade foi agregada pelo predomínio da visualidade (característica dos materiais escritos), transformando a espacialidade urbana, e os modos de se relacionar. Mudanças mais radicais ocorreram a partir do século XVIII com a criação das mídias técnicas baseadas na eletricidade com a possibilidade de reprodução em massa. Dentre as mídias técnicas, o telégrafo ocupa lugar essencial nas reflexões de Kittler e outros estudiosos, apresentado como uma tecnologia capaz de transportar o pensamento humano através do ar, pela eletricidade e visto como um ancestral do modo de comunicação estabelecido pela internet, tendo causado grande impacto na economia e hábitos. $O$ advento das mídias técnicas trouxe simultaneidade das relações sociais à distância. No entanto, foi a comunicação digital, com a microeletrônica, desenvolvida a partir do final dos anos 1930, que permitiu a armazenagem, indexação e processamento ágil de grande quantidade de informações, transformando a espacialidade da interação social com a simultaneidade nas práticas sociais.

Criar Educação, Criciúma, v. 8, nº1, jan/jul 2019.- PPGE - UNESC 


\section{CRIAR EDUCAÇÃOO Revista do Programa de Pós-Graduação em Educação - UNESC}

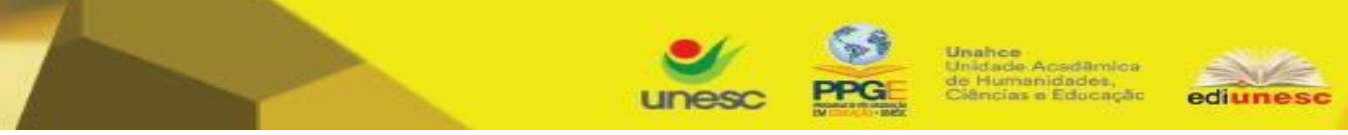

No contexto educacional brasileiro, temos percebido a presença cada vez maior dos dispositivos móveis e outras tecnologias emergentes nas salas de aula. No entanto, essas tecnologias, apesar de disponíveis, não estão integradas da maneira como se esperava.

Tais mudanças exigem reconfigurações no cenário educacional e no desenvolvimento de propostas que abram caminhos para novas formas de pensar e de produzir o conhecimento. Já se passaram 20 anos desde a popularização das mídias digitais no Brasil e a escola continua "sendo pressionada a fazer algo que ocorre muito mais fluidamente fora de seus muros - que a propósito, continuam lá" (RIBEIRO, 2016, p. 94).

Nesse sentido, as novas relações de aprendizagem estabelecidas por meio da tecnologia passam a ganhar espaços de discussão. É o que percebemos na Base Nacional Comum Curricular (BNCC) (BRASIL, 2018), documento que direciona a aprendizagem na Educação Básica, ao nortear o uso da tecnologia pelos professores e alunos. Isso porque, entre as 10 competências gerais da BNCC, duas enfocam as tecnologias digitais, reconhecendo as ferramentas digitais como grandes aliadas no desenvolvimento pedagógico cognitivo e socioemocional. Predominam duas vertentes de discussão quanto às competências tecnológicas na BNCC: uma delas, prevista na competência 4 da Base, diz respeito ao 'digital' enquanto linguagem que se estabelece para uso e construção e outra, prevista na competência 5, norteia quanto ao senso crítico e ético com que se deve utilizar e compreender o uso dessa tecnologia, conforme trecho a seguir que detalha a competência 5 :

Compreender, utilizar e criar tecnologias digitais de informação e comunicação de forma crítica, significativa, reflexiva e ética nas diversas práticas sociais (incluindo as escolares) para se comunicar, acessar e disseminar informações, produzir conhecimentos, resolver problemas e exercer protagonismo e autoria na vida pessoal e coletiva. (BNCC, 2018, p.09)

Criar Educação, Criciúma, v. 8, nº1, jan/jul 2019.- PPGE - UNESC 


\section{CRIAR EDUCAÇÃOO Revista do Programa de Pós-Graduação em Educação - UNESC}

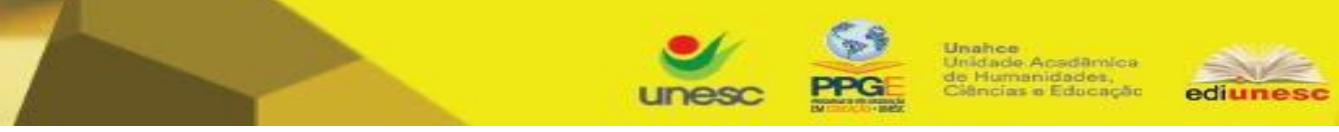

Podemos avançar em nossa reflexão entendendo que tal enfoque da BNCC perpassa os pressupostos de Paulo Freire, em 'Educação como prática da liberdade', de 1980, quanto à autonomia, cidadania e prática pedagógica. Freire estabelece uma interrelação entre comunicação e educação, para quem era necessário apropriar-se das tecnologias, com critérios, para reavivar a humanização do homem. Segundo o autor, a comunicação é o elemento pelo qual é possível transformar o ser humano em sujeito da sua própria história, que o conduz a uma consciência crítica e a uma transformação.

A presente reflexão, dessa maneira, situa-se nos rastros dessas problemáticas apresentadas, com enfoque na formação docente, nas interfaces com a educação e comunicação, entendendo que a nova forma de funcionamento das mídias na era da convergência reconfigurou a relação entre os alunos, os professores e as corporações, transformando a maneira como se produz, se assiste e se distribuem os conteúdos educacionais, tais como as narrativas digitais contemporâneas.

\section{A formação docente em um ambiente midiático e inclusivo}

No âmbito da formação docente, as tecnologias digitais podem auxiliar no aperfeiçoamento da base conceitual e das propostas pedagógicas dos professores, contribuindo para que consigam atender às novas demandas que a profissão lhes coloca. Para a perspectiva histórico-cultural, o uso de instrumentos é o que possibilita que o homem transforme a natureza e a si mesmo, em

uma relação dialética (PINO, 2000). Entendemos que as tecnologias digitais são instrumentos culturais e como tal, transformam o homem, inclusive em seu aparato biológico e em suas relações sócio-culturais, como podemos verificar no mundo contemporâneo. Assim, as escolas como espaços sociais deveriam incorporar essas novas tecnologias.

Além das propostas em relação a incorporação das tecnologias digitais nas escolas, entendemos que na Política de Inclusão feita pelo governo, há ainda um caminho a ser percorrido (JESUS; BATISTA; CAIADO, 2013) e, as tecnologias digitais configuram-se como um espaço de grande contribuição. Segundo Ferreira (2014), o trabalho a ser 


\section{CRIAR EDUCAÇÃOO Revista do Programa de Pós-Graduação em Educação - UNESC}

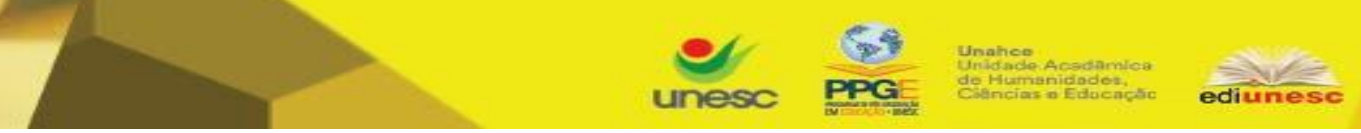

Atualmente, as mídias móveis, tais como os tablets e celulares, além de atuarem como fontes de entretenimento e comunicação, permitem tanto criação, distribuição e acesso a conteúdos audiovisuais. Tal característica é essencial para compreendermos as possibilidades oferecidas às produções de narrativas digitais. Tendo essas possibilidades em mente, podemos pensar que o desenvolvimento das Tecnologias de Informação e Comunicação (TICs) tem propiciado significativa mudança nas mídias tradicionais principalmente no que diz respeito às reconfigurações da linguagem narrativa que produzem novos objetos estéticos e diferentes concepções na relação entre as mídias e seus espectadores.

O uso crescente de aparelhos portáteis permite às pessoas entrarem em contato umas com as outras em torno de temas de interesse comum, seja para trocar experiências, resolver problemas ou criarem e compartilharem conteúdos audiovisuais. $\mathrm{Na}$ medida em que os novos recursos, além das câmeras, foram incorporados ao smartphone e tablets, como giroscópio, acelerômetro e maior capacidade de processamento, experiências radicalmente novas foram incorporadas às narrativas audiovisuais. Essa potencialidade deriva das suas propriedades essenciais: a imersão em múltiplas linguagens, a conectividade, a geolocalização e o agenciamento de novas formas de narratividades.

Quando pensamos em interatividade, essa noção traz particularidades em se tratando das mídias móveis como smartphones e tablets. A escolha pelo uso de ferramentas disponíveis em tablet como nosso objeto de estudos se deu principalmente por ser um dispositivo que inclui em seu sistema operacional funções próximas às de um computador pessoal, além da possibilidade de acesso à web. Tornou-se viável estabelecer interações mediadas que incorporam diversos elementos das interações presenciais, devido à possibilidade de manipulação da voz, do som ambiente e da imagem dos sujeitos em interação (VALENCISE-GREGOLIN, 2012).

Assim, na atualidade, a presença das diversas mídias no cotidiano dos indivíduos impacta em profundas mudanças culturais, criando desafios para a produção e distribuição de conteúdos audiovisuais. Trata-se de um período de reconfiguração do

Criar Educação, Criciúma, v. 8, nº1, jan/jul 2019.- PPGE - UNESC 


\section{CRIAR EDUCAÇÃOO Revista do Programa de Pós-Graduação em Educação - UNESC}

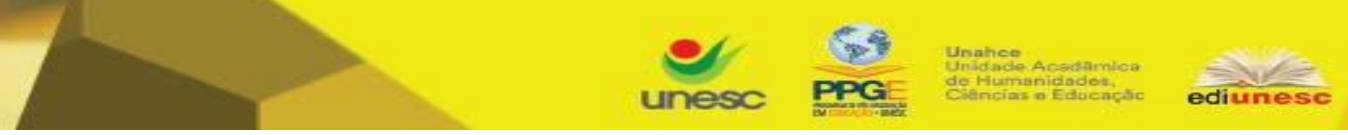

ecossistema em si, em que muitas ações são ainda exploratórias enquanto buscam formas de adaptação ao contexto de fluxo de conteúdos entre diversas plataformas de mídia.

Acreditamos que as ferramentas de criação de narrativas digitais, tais como Toontastic e Educreations, diante desse contexto de transformações, contribui com novos olhares para a construção de saberes e o desenvolvimento de habilidades cognitivas.

A 'narrativa' é uma forma artesanal de comunicação com raízes na tradição oral dos povos, assim, narrar é a habilidade de "intercambiar experiências". (BENJAMIN, 1987, p. 205). A 'narrativa digital' aproxima as múltiplas linguagens difundidas nos meios digitais (constituídas pela convergência tecnológica e pela conectividade) trazendo "não apenas novas formas de acesso à informação, mas também novos processos cognitivos, novas formas de conhecimento". (Soares, 2002, p 152),

Essas características fazem das narrativas em um meio digital, um poderoso recurso, ao oferecer aos indivíduos a imersão em outros mundos, envolvendo-os em deslocamentos para que se obtenha novas perspectivas e ângulos de visão.

Isso porque as ferramentas digitais, tais como os aplicativos Toontastic e Educreations, convidam os usuários, de maneira colaborativa, a criar e participar do processo de elaboração da história. $O$ antigo espectador passivo pode assumir uma postura ativa, de interator e usuário, capaz de conduzir uma narrativa, de montar e remontar um conteúdo, de negociar e discutir um assunto em tempo real. As mídias móveis potencializam esta capacidade, com suas possibilidades de mobilidade, interatividade e instantaneidade.

A noção de engajamento passa a ser mais importante que a noção de audiência. Esse novo paradigma transforma a maneira como o espectador se relaciona com 0 ambiente midiático multiplataforma e com o conteúdo audiovisual. Neste sentido, a convergência midiática proporciona às audiências a oportunidade de dialogar com produtos que seguem uma lógica complexa.

A seguir faremos um relato da experiência e resultados parciais obtidos com essa investigação, apresentando os aspectos metodológicos que permeiam a investigação. 


\section{CRIAR EDUCAÇÃOO Revista do Programa de Pós-Graduação em Educação - UNESC}

\section{dológicos}

Iniciamos os procedimentos metodológicos partindo de revisão de literatura sobre os temas que permeiam esta pesquisa: cultura digital, formação docente e ferramentas digitais.

As reflexões aqui apresentadas se baseiam nos resultados obtidos com intervenções conduzidas em sala de aula com alunos, numa primeira etapa e com docentes, na etapa atual. Nessa investigação, levantamos questões que nortearam nossa reflexão, procurando entender de que maneira o uso dessas ferramentas digitais instiga o professor a elaborar estratégias que favoreçam a inclusão. Ainda, procuramos entender quais os desafios e possibilidades encontradas a partir dessas práticas.

Utilizamos a metodologia qualitativa de pesquisa e os dados foram observados sob a perspectiva histórico-cultural, em que a análise é interpretativa, instaurada em um contexto sócio-histórico (VIGOTSKI, 2007). Dentre os instrumentos utilizados para coleta, os docentes caracterizaram nossos sujeitos participantes da pesquisa, as notas de campo trouxeram detalhes subjetivos percebidos pelas pesquisadoras. As entrevistas com as professoras ocorreram após os períodos de intervenção e permitiu entendermos melhor os resultados dessa experiência.

A realização ocorreu em diferentes períodos ao longo de 2 meses em 2018, através de entrevistas com as professoras. A conclusão dessa etapa se deu com um plano de ação para as próximas etapas. Na segunda etapa, adotamos estratégias didáticas para entender como as docentes percebiam as possibilidades dos recursos tecnológicos e, na terceira etapa, a pesquisadora trouxe os celular e tablet para a sala de aula, apresentando o aplicativo Toontastic e, posteriormente, o aplicativo Educreations com o intuito de entender como as docentes se apropriavam das ferramentas para construir narrativas digitais em seus contextos. Para escolhermos esses dois aplicativos, conduzimos uma primeira etapa em que exploramos outros aplicativos similares que tinham a mesma proposta de criação de narrativas animadas. Alguns critérios foram aplicados na escolha: 
queríamos que fossem gratuitos; que estivessem disponíveis nas plataformas móveis (tablet e/ou celular); desejávamos que explorassem os recursos dos

dispositivos móveis, tais como o microfone para captura de voz e o recurso de gravação de vídeo; queríamos que possibilitassem ao professor criar grupos e compartilhar as animações em uma galeria. Ainda, necessariamente deveriam, além de oferecer uma variedade de elementos visuais e sonoros para a criação, precisariam disponibilizar a opção de o aprendiz criar seu próprio conteúdo pelo recurso do desenho e escrita.

\section{Resultados e Discussão}

Para a condução das atividades junto aos docentes, fizemos uso de dois aplicativos distintos, o Toontastic e Educreations, escolhidos pois nos pareceram ferramentas de fácil manuseio, ao permitir que se produza de maneira autônoma e colaborativa narrativas animadas pelo uso da tela tátil adicionando e criando objetos e usando o microfone do dispositivo para a gravação de vozes.

Nas intervenções conduzidas em grupos focais, deixamos os docentes livres para escolherem se desejavam utilizar as ferramentas via tablet ou telefone celular, independente do sistema operacional (Android ou iOS).

$O$ fato de o Toontastic oferecer uma grande variedade de temas faz dele uma rica ferramenta de autoria para construção das narrativas, porém, essa variedade de temas se mostrou um desafio às professoras. Percebemos que é preciso levar em conta que, quando a se explora um aplicativo pela primeira vez, o usuário quer conhecer todas as opções de personagens e objetos e se diverte nesse processo de escolha. Isso faz com que dedique boa parte do tempo nessa etapa e perca o foco da atividade proposta. 


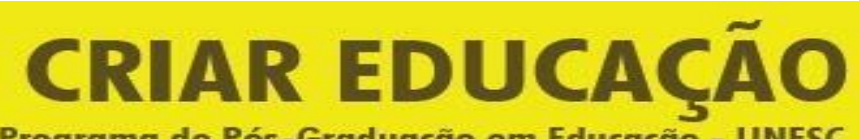

Revista do Programa de Pós-Graduação em Educação - UNESC

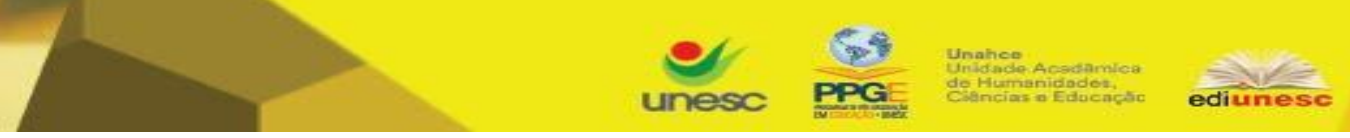

Figura 01: montagem com elementos visuais do aplicativo Toontastic

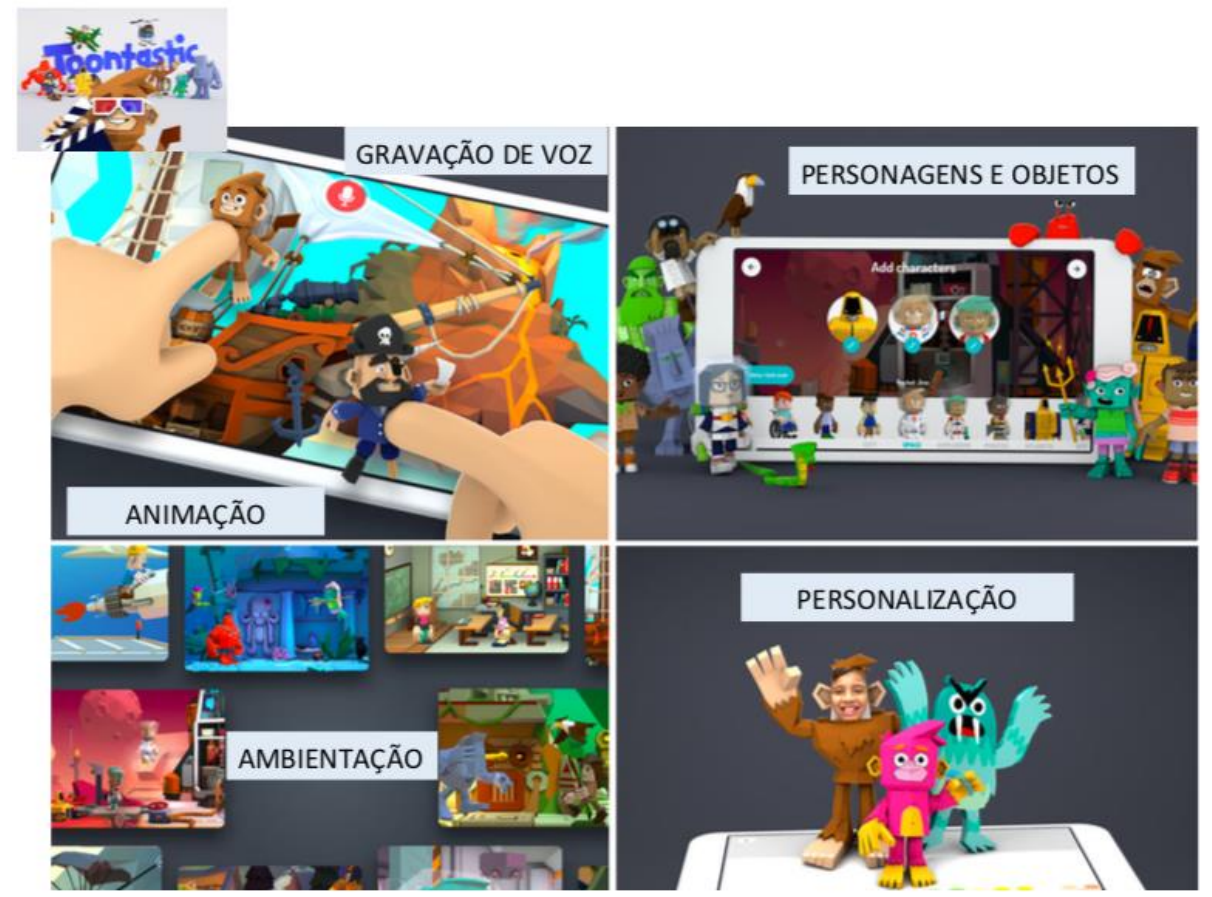

As narrativas, assim, são meios de sociabilidade, pois através delas as experiências individuais são comunicadas e tornadas "públicas" ou socialmente conhecidas. (HANKE, 2003)

O recurso digital permite que se criem desenhos que aparecem animados nas cenas. $O$ desenho se mostrou uma forma de expressão que se adequa a diferentes perfis de crianças. Fizemos outras atividades com a etapa de desenho e pudemos validar nossa ideia inicial.

Dentre as práticas que mais se destacaram, em um caso, o docente propôs uma atividade em que o aprendiz deveria levantar uma narrativa clássica e utilizar o Toontastic de maneira criativa para recriar a cena e contar novos finais. Outros quiseram efetuar atividades de reconto em que há a leitura de uma narrativa em livro e então a ferramenta é utilizada para recriar cenas ou momentos da história lida anteriormente. Outra forma de uso seria reforçar um conteúdo dado ou mesmo aplicar como uma maneira interativa de fazer a avaliação.

Criar Educação, Criciúma, v. 8, nº1, jan/jul 2019.- PPGE - UNESC 
Assim, pudemos perceber que os tipos de atividades com o Toontastic que mais se mostraram promissoras aos docentes foram aquelas que partiam de uma história pré existente para se basear. Possivelmente pela possibilidade de se trabalhar temas transversais ou temáticas atuais, como no reconto do livro sobre a história da Malala, ou quando a proposta era que os aprendizes contassem uma versão da história da Chapeuzinho Vermelho dos dias atuais.

As intervenções com o Toontastic despertaram interesse que as professoras envolvidas nas atividades procurassem outras ferramentas digitais que também pudessem auxiliá-las em aula, dando continuidade às práticas mesmo depois de finalizado o período de investigação.

Após nossas experiências, essas professoras mudaram suas visões e entenderam que o fato de estarem disponíveis em língua inglesa não era impeditivo para a compreensão pelo aprendiz.

Isso permite que se aumente as possibilidades, não precisando restringir suas buscas aos aplicativos nacionais.

A partir de suas falas, percebemos que, antes das intervenções, as professoras se mostravam relutantes em procurar por ferramentas pelo fato de desconhecerem tais possibilidades de uso. Tal situação nos levou a perceber que, termos apresentado uma variedade de ferramentas a serem exploradas, despertou ainda mais interesse nessa descoberta por outras ferramentas pelas professoras.

Criar Educação, Criciúma, v. 8, nº1, jan/jul 2019.- PPGE - UNESC 
Figura 02: interface gráfica do aplicativo Educreations

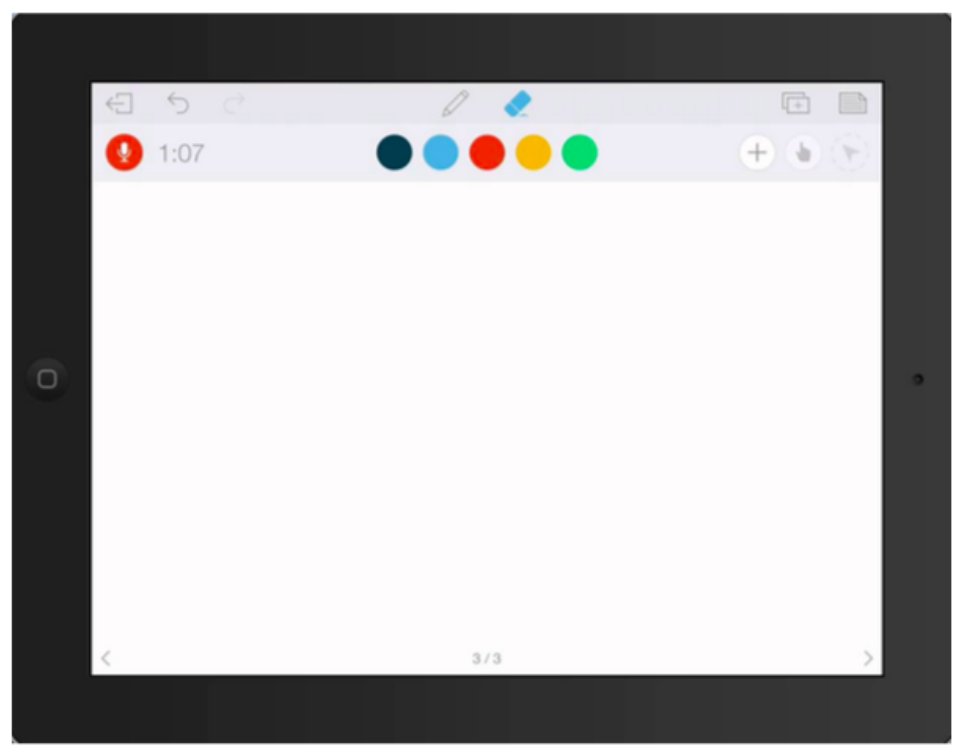

As entrevistas que conduzimos nesse período apontaram que as professoras tiveram uma motivação especial nessa busca por ferramentas quando vislumbraram a possibilidade de envolver alunos em política de inclusão nas atividades. O uso do desenho e da gravação de voz para construir as histórias se mostraram condições

Figura 02: interface gráfica do aplicativo Educreations

0

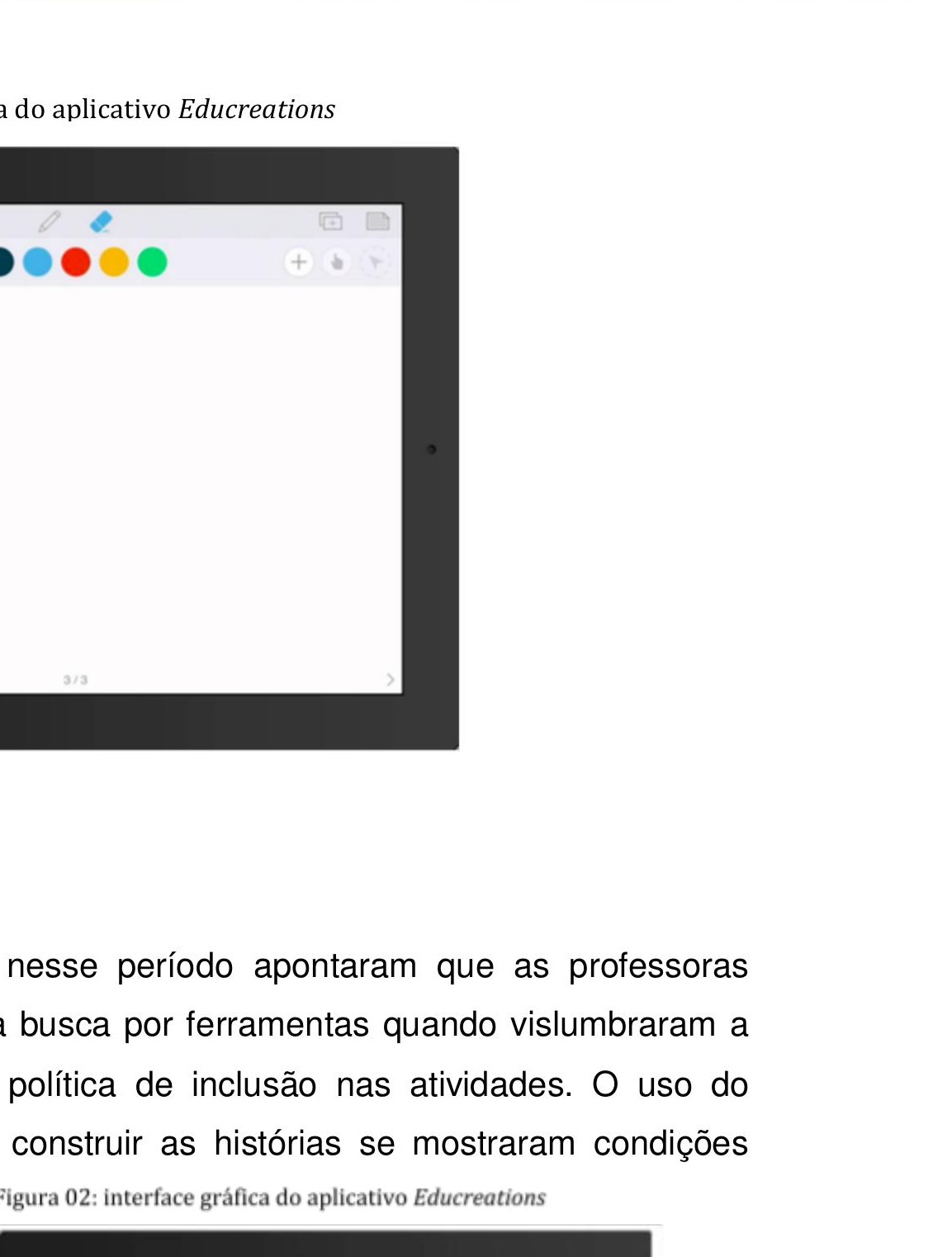

essenciais para as práticas inclusivas.

Criar Educação, Criciúma, v. 8, nº1, jan/jul 2019.- PPGE - UNESC 


\section{CRIAR EDUCAÇÃO Revista do Programa de Pós-Graduação em Educação - UNESC}

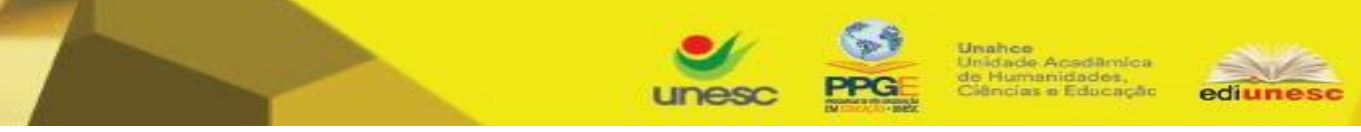

Foi nesse contexto, na segunda etapa das intervenções, que optamos pelo uso do aplicativo Educreations, uma ferramenta que simula um quadro branco que permite ao usuário desenhar, escrever e até mesmo narrar o que aparece na tela. Inicialmente, acreditávamos que o fato de ser uma ferramenta diferente do Toontastic traria uma insegurança para as professoras. No entanto, isso não ocorreu, pelo contrário, por terem explorado anteriormente o Toontastic, já conseguiam associar alguns recursos que se assemelhavam e pareciam bastante familiarizadas com a nova ferramenta desde o início.

Outra hipótese que tínhamos, logo desconstruída, era a ideia de que o Educreations , por não trazer elementos visuais lúdicos como personagens e cenários pré estabelecidos, não seria tão estimulante ao aprendiz. Pelo contrário, apesar de não trazer os elementos, o Educreations permite que o aprendiz acesse a internet e adicione imagens, animações e sons disponíveis na rede.

Segundo as professoras, em função desse recurso, o Educreations se mostrou flexível o suficiente para criar narrativas mais incrementadas em suas práticas diárias, adequando-se a conteúdos distintos. Tal aspecto levou as professoras a entenderem o Toontastic como mais adequado aos aprendizes do universo infantil e infanto-juvenil e o Educreations, aos jovens e adultos.

\section{CONSIDERAÇÕES}

Apesar de ser uma pesquisa em andamento, os resultados parciais obtidos são encorajadores, indicando que as ferramentas digitais, como Educreations e Toontastic enquanto instrumento de acessibilidade e inclusão, podem auxiliar o professor favorecendo a comunicação e socialização entre os aprendizes. Os resultados apresentados indicam que houve mudanças profundas na maneira como as professoras observam suas ações e reflexões quanto a suas práticas pedagógicas e as possibilidades de transformação dessas práticas a partir do uso das ferramentas digitais, o que corrobora com as propostas teóricas de formação de professores aqui apresentadas.

Criar Educação, Criciúma, v. 8, nº1, jan/jul 2019.- PPGE - UNESC 


\section{CRIAR EDUCAÇÃOO Revista do Programa de Pós-Graduação em Educação - UNESC}

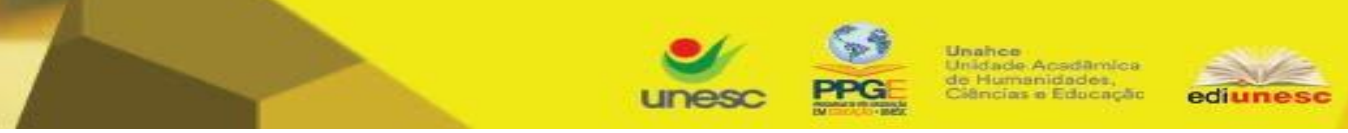

Os resultados de nossa investigação apontam para a necessidade de se buscar ferramentas digitais diversificadas, indo além daquelas já selecionadas previamente e oferecendo outras possibilidades ao docente. Fato observado ao incorporarmos em nossa pesquisa a ferramenta Educreations, tendo se mostrado flexível o suficiente para que os docentes pudessem vislumbrar criar narrativas em suas práticas diárias, adequando-se a conteúdos distintos e junto a aprendizes de diferentes idades.

As tecnologias digitais, ao aperfeiçoar as habilidades pedagógicas inserindo os professores no processo inclusão na cultura digital, contribuem para que consigam atender às novas demandas que a profissão thes coloca.

Sob essa perspectiva, podemos entender que, ao fazer uso das ferramentas digitais por meio das mídias móveis em suas práticas pedagógicas, os professores se inserem nos princípios norteadores da BNCC ao preverem o uso de diferentes linguagens (digital, visual, verbal, sonora, textual) para partilhar conhecimentos e produzir sentidos em diferentes contextos.

Como impacto direto das experiências conduzidas, percebemos que as professoras sentiram-se seguras e motivadas em modificar suas práticas e experimentar novas formas de ensinar.

Os dados obtidos até o momento ajudaram a redesenhar as próximas etapas da investigação. Na etapa atual da investigação, as pesquisadoras direcionaram seus focos no uso da ferramenta Educreations, que se mostrou uma forte aliada ao docente na criação de aulas e apresentação de conceitos de maneira lúdica e interativa, com base em narrativas digitais.

$\mathrm{Na}$ próxima etapa da pesquisa, pretendemos compreender como os docentes se apropriam das tecnologias em seus contextos de aula, em suas práticas pedagógicas no cotidiano, de maneira que nos forneça bases norteadoras para a formação docente e quanto ao uso de ferramentas de criação de narrativas digitais, em uma proposta colaborativa de formação continuada. Dessa maneira, acreditamos poder contribuir efetivamente para a formação e prática cotidiana dos professores.

Criar Educação, Criciúma, v. 8, no1, jan/jul 2019.- PPGE - UNESC 
Pretendemos organizar essas novas práticas na próxima etapa da pesquisa, compartilhando com a comunidade acadêmica e em formações docentes quanto ao uso das ferramentas digitais, contribuindo para a continuidade desses trabalhos iniciados.

Por fim, refletir sobre a proeminência das mídias nos ajuda a entender como elas se cristalizaram em nosso cotidiano a ponto de não mais nos darmos conta da mudança perceptiva operada por cada um dos desenvolvimentos tecnológicos que moldaram a vida atual. Por se tratar de um campo de estudos relativamente recente, as pesquisas sobre as inter-relações entre o uso das tecnologias digitais na educação e a formação docente ainda não apresentam um conjunto canônico de teorias. Esta reflexão, decerto, não esgotou todas as possibilidades que o tema pode

suscitar. Pelo contrário, incita novas inquietações que podem nortear debates futuros para pensarmos diferentes formas narrativas na formação docente de forma crítica e ética, discutindo as dimensões das novas experiências sociais que as tecnologias digitais podem engendrar.

\section{REFERÊNCIAS}

AMANTE, L. Infância, escola e novas tecnologias. In: COSTA, F. A.; PERALTA, H.; VISEU, S. (Orgs.). As TIC na Educação em Portugal: concepções e práticas. Porto: Editora Porto, 2007.

BRASIL. Base Nacional Comum Curricular (BNCC). Educação é a Base. Brasília, MEC/CONSED/UNDIME, 2018. Disponível em:

$<$ http://basenacionalcomum.mec.gov.br/wp-content/uploads/2018/02/bncc-20dez site.pdf.> Acesso em: Junho de 2018. ,

CAMARGO, E.A.A.; MONTEIRO, M.I.B.; FREITAS, A.P. de. Trabalho docente no contexto da inclusão: formação continuada com enfoque colaborativo. Rev. Educ. PUC Campinas, 21 (1): 45-57, jan./abr., 2016.

FERREIRA, M.C.C. Prefácio. IN: MONTEIRO, M.I.B.; FREITAS, A.P.de; CAMARGO,E.A.A.(orgs) Relações de Ensino na Perspectiva Inclusiva: alunos e professores no contexto escolar. Araraquara: Junqueira \& Marin Editores, p.13-22, 2014.

FLORIDI, L. (Ed.) The Onlife Manifesto: Being Human in a Hyperconnected Era. London: Springer, 2015.

Criar Educação, Criciúma, v. 8, nº1, jan/jul 2019.- PPGE - UNESC 
FREIRE, Paulo; GUIMARÃES, Sérgio. Educar com a mídia . São Paulo:Paz e Terra, 2011.

FREIRE, Paulo. Educação como prática da liberdade. 23a ed. Rio de Janeiro: Paz e Terra, 1999.

HANKE, M. Narrativas Orais: formas e funções. Contracampo, vol 9, no 1, 2003.

JESUS, D.M.; BATISTA, C.R.; CAIADO, K.R.M. Atendimento Educacional Especializado: anunciando múltiplas lentes. In: JESUS, D.M.; BATISTA, C.R.; CAIADO, K.R.M. Prática

Pedagógica na Educação Especial: multiplicidade do atendimento educacional especializado. Araraquara, SP: Junqueira \& Marins, p. 11-20, 2013.

KITTLER, Friedrich. A história dos meios de comunicação. In: Lúcia Leão (org.). 0 chip e o caleidoscópio: reflexões sobre as novas mídias. São Paulo: Editora SENAC, 2005.

MONTEIRO, M.I.B.; CAMARGO,E.A.A.; FREITAS, A.P. de. Reflexões sobre práticas de ensino e inclusão. Journal of Research in Special Educational Needs .Volume 16. Number s1, p.940-944, 2016.

NÓVOA, A. Para uma formação de professores construída dentro da profissão. IN:NÓVOA, A. (org). Professores: imagens do futuro presente. Lisboa: Educa, 2009. p. 25-46.

PINO, A.S. O social e o cultural na obra de Lev S Vigotski. Vigotski - O Manuscrito de 1929. Educação e Sociedade, n. Especial, 71, p. 45-78, jul. 2000.

PINO, A.S. Técnica e semiótica na era da informática. Contrapontos, Itajaí, V. 3, n. 2, p. 283-296, mai./ago, 2003.

RIBEIRO, Ana Elisa. Tecnologia digital e ensino: breve histórico e seis elementos para a ação. Revista Linguagem \& Ensino (Online), v. 19, p. 91-111, 2016.

SOARES, M. Novas práticas de leitura e escrita: letramento na cibercultura. Educação \& Sociedade . Campinas, vol. 23, n. 81, p. 143-160, dez. 2002 . Disponível em <http://www.cedes.unicamp.br> ACESSO em: outubro de 2012.

VALENCISE-GREGOLIN, M. Mobilidade e cultura participativa: transformações da ação social contemporânea. Tese (Doutorado em Artes Visuais) - Instituto de Artes. Universidade Estadual de Campinas. 2012.

VYGOTSKI, L.S. Obras escogidas V: fundamentos de defectologia. Madrid: Visor, 1997.

VIGOTSKI, L. S. A Formação Social da Mente. São Paulo: Martins Fontes, 1991.

VIGOTSKI, L. S. A Construção do Pensamento e da Linguagem. São Paulo: Martins

Criar Educação, Criciúma, v. 8, nº1, jan/jul 2019.- PPGE - UNESC 
Fontes, 2001.

VIGOTSKI, Lev. S. Imaginação e criação na infância: ensaio psicológico. Apresentação e comentários de Ana Luiza Smolka. São Paulo: Ática, 2009.

Recebido em Março 2019

Aprovado abril 2019

Criar Educação, Criciúma, v. 8, nº1, jan/jul 2019.- PPGE - UNESC 